Western University

Scholarship@Western

FIMS Publications

Information \& Media Studies (FIMS) Faculty

2017

\title{
Motivations for Sharing News on Social Media
}

Lorraine (Lola) Y.C. Wong

Western University, lola.wong@uwo.ca

Jacquelyn Burkell

The University of Western Ontario, jburkell@uwo.ca

Follow this and additional works at: https://ir.lib.uwo.ca/fimspub

Part of the Library and Information Science Commons

Citation of this paper:

Wong, Lorraine (Lola) Y.C. and Burkell, Jacquelyn, "Motivations for Sharing News on Social Media" (2017). FIMS Publications. 163. https://ir.lib.uwo.ca/fimspub/163 


$\begin{array}{cc}\text { Motivations for Sharing NewS on Social Media } \\ \text { Jacquelyn Burkell } \\ \text { W.Y.C. Wong } \\ \text { Western University } \\ \text { Western University } \\ \text { Faculty of Information and Media } \\ \text { Studies } & \text { Faculty of Information and Media } \\ \text { Studies } \\ \text { FIMS and Nursing Building, Rm } 2020 & \text { FIMS and Nursing Building, Rm } 2020 \\ 519-661-2111 \text { ext } 88506 & 519-661-2111 \text { ext } 88506 \\ \text { lola.wong@ @uwo.ca } & \text { jburkell@uwo.ca }\end{array}$

\begin{abstract}
Social media have become an important part of everyday communication, and a platform for sharing and 're-sharing' of information. We discover news through our social networks and pass some of what we encounter along to others in those same networks. Numerous studies focus on the sharing of personal information (both online and offline) but less research examines practices related to the sharing of news — especially sharing via social media. Understanding why we choose to share news and non-personal content online is vital in a world where we increasingly turn to social media and our online social networks for news and information about the world around us. This research explores factors that influence our decision to share and re-share non-personal content with others in an online environment, specifically the choices we make when we share news.
\end{abstract}

\title{
CCS Concepts
}

- Information systems $\rightarrow$ World Wide Web $\bullet$ Applied computing $\rightarrow$ Law, social and behavioral sciences $\cdot$ Human-centered computing $\rightarrow$ Collaborative and social computing $\rightarrow$ Collaborative and social computing systems and tools

\section{Keywords}

Social media; News sharing; Motivations; Gratifications.

\section{INTRODUCTION}

We make choices when we share information on social media: we choose what we want to share and with whom. The decision to share information about ourselves appears to be influenced by (i) the type of information, (ii) the audience with which information is shared, and (iii) the benefit that can be gained by the sharing of information. The factors that influence the decision to share personal content online, however, may differ from why we share news with others online. And, as social media becomes a prominent source of news for a significant part of the population, understanding why we share what we share becomes important. As Mitchell [11] asserts, "[C]hanging news habits have a tremendous impact on how and to what extent our country functions within an informed society. So, too, does the state of the organizations producing the news and making it available to citizens day in and day out." The exchange of news in the online environment is worthy of attention as more of the population use social media every day to interact. It behooves us to understand the news sharing process in the online environment because our social networks now curate the content that comes across our news feeds. This research is an exploratory study of the factors that influence our decision to share and re-share nonpersonal content and news with others in an online environment.

\section{RELATED WORK}

Previous studies have explored psychological and sociological perspectives on the motivation to share personal information, both in offline and online environments. People share content to enhance the lives of others within their networks, and to define themselves within those communities [5]. Bjoran [5] suggests that, according to Maslow's Hierarchy of Needs, people share for self-esteem and self-actualization. People may share "practically useful content for altruistic reasons (e.g., to help others) or for self-enhancement purposes (e.g., to appear knowledgeable)" [3]. Research such as a study conducted by The New York Times (NYT) [15] identifies five motivations for why people share online: (i) to deliver valuable and entertaining content, (ii) to define themselves to others, (iii) to feel like part of something larger, (iv) to stay connected to close ones, and (v) to promote causes and

Permission to make digital or hard copies of all or part of this work for personal or classroom use is granted without fee provided that copies are not made or distributed for profit or commercial advantage and that copies bear this notice and the full citation on the first page. To copy otherwise, or republish, to post on servers or to redistribute to lists, requires prior specific permission and/or a fee.

SMSociety'17, July 28-30, 2017, Toronto, ON, Canada.

(c) 2017 Copyright held by the owner/author(s). Publication rights licensed to ACM.

ACM 978-1-4503-4847-8/17/07...\$15.00.

DOI: http://dx.doi.org/10.1145/3097286.3097343 
self-fulfillment. This NYT study suggests primary motivators for sharing online but does not distinguish the sharing personal updates from sharing non-personal content. This paper attempts to identify motivations for sharing news and other non-personal information. As Turner [16] points out, 'motivation' is a challenging and complicated concept; moreover, motivations are not always conscious, and thus not always open to introspective report [7]. Recognizing these limitations, we nonetheless argue that the results of this exploratory study will provide insight into the consciously available motivations behind the sharing of news and other non-personal content.

We share more than just content about ourselves on social media. We also share news to keep each other abreast of events around us. What, then, motivates people to share content that is from an external source (and by external, we mean not personally generated)? Ostensibly, factors that influence the motivation to share non-personal content are similar to personal content sharing. Sharing any content on social media appears to be influenced by (i) the content itself, (ii) the receiving audience, (iii) the relationship between the recipient and the sender, and (iv) an inherent desire or need of the sharer. The decision to share a link to a news story, however, may be very different from the choice to share a personal update. Sharing non-personal content (or the decision not to share that content) may have a different set of criteria than sharing personal updates.

Social media and technology have changed the way news is consumed and shared. Traditionally, news was meticulously produced and disseminated to the public in a curated format. Former audiences were habituated to receiving their news at set hours and in neatly packaged formats, such as newspapers [10]. Now, audiences live within a constant buzz of ambient news, available any time, anywhere on almost any device, produced both by professionals and the audience itself [10]. The most apparent shift, however, is where we receive our news nowadays - our online social networks. Today, a large portion of the population receives news through their social circle via social media platforms: $62 \%$ of U.S. adults overall now get news on social media sites [8] and younger adults are more likely to name social media as their main source of news [12]. According to Barthel et al. [1] the "majorities of Twitter (63\%) and Facebook users (63\%) now say each platform serves as a source for news about events and issues outside the realm of friends and family" - an increase of $>10 \%$ since 2013. Our friends, family, and acquaintances on social media are populating and curating the news we see. And, we in turn are consuming and resharing that content with our social networks. These processes have become habitual, and we are discovering news through avenues not previously available. Gone is the metaphorical 'water cooler', as we now share news and communicate with people without face-to-face contact, and inadvertently discover news articles through our much broader social networks [4]. Social media have not only changed the way we share news, but the way we interact with each other in general. Both face-to-face and online interactions have advantages and disadvantages. Sharing information online allows for asynchronous communication for those in different time zones and locations while face-to-face interaction allows physical cues such as facial expressions and body language [13].

Technology, social media platforms and applications have facilitated news sharing by providing convenient and easy-to-use tools for posting content; people have grown accustomed to seeing the ubiquitous buttons and links for social sharing and undeniably use them. On both Facebook and Twitter, approximately a quarter of all users post or tweet about news "at least sometimes" [2]. On the subject of Facebook in particular, Chang [6] 
observes, "It's become one of the primary news sources of our time, and Facebook owes much of its success to the plethora of content its users share on a daily basis. The over one billion daily users of Facebook aren't simply lurking on the social network, but rather pushing out new information to their friends and followers."

Despite the missing visual cues from being face-to-face, we can effectively share all types of content online with those near and far to us both geographically and emotionally. Instances of sharing on social media now include more than the exchange of personal details. People now share and re-share news; what we choose to share and with whom is influenced by why we want to share it. Do the same three factors of 'who', 'what' and 'why' influence the decision to share news? This research explores factors that influence our decision to share and re-share non-personal content with others in an online environment, specifically the choices we make when we share news.

\section{METHOD}

We explore why people choose to share news online using a combination of qualitative research techniques. Interviews and focus groups were conducted to allow for broad discussion about online news sharing including the type of information, with whom the information is shared, and how or in what context. This study was exploratory in nature; the objective was to observe considerations participants made when asked to describe their process when sharing news and non-personal content. Using a semi-structured interview approach in both one-on-one and group discussions provided an opportunity to gather an overview of online news sharing practices.

18 participants between the ages of 18-30 were recruited from a South-Western Ontario university in March 2015. Five interviews, approximately one hour each, were conducted over a two-week period in a small conference room on campus or in the privacy of the participant's home. Two 60 minute focus group sessions were held in a small conference room on campus; one session consisted of 5 female participants and 1 male, the other consisted of 4 females and 3 males. Different examples of news and non-personal content were used to prompt discussion including articles about the riots in Ferguson, the 'Blue \& Black dress' viral meme, and videos of a cat riding a robot vacuum. Participants were given the opportunity to scroll through their social media feeds to remind them of news content they had shared. The audio was recorded for each interview and focus group, and recordings were later transcribed. Transcriptions were coded using the qualitative data analysis software HyperResearch. Using the constant comparative method [14], comments from the participants were analyzed.

\section{RESULTS \& DISCUSSION}

Participants indicated a variety of reasons for sharing news online. Comments revealed that the basic reason for sharing non-personal content was to inform, entertain, or some combination of the two. When prompted with examples of news subjects or viral content and asked questions about different instances of sharing, participant discussion indicated that personal beliefs or intentions could also influence the decision to share beyond the basic motivation to inform and entertain.

\subsection{Basic Reasons for Sharing News}

In every instance of sharing news or non-personal content described by participants, the motivation was to inform, to entertain, or some blend of the two. We define 'sharing to 
inform' as sharing content to bring awareness to an issue or an event, to help or assist with a problem, or sharing something that has potential value to the intended audience. There are, however, instances where sharing is not solely about informing, at least not in the formal sense: sometimes people share things to entertain others. While this 'entertaining' type of sharing still brings attention to news or non-personal content, the underlying goal is to amuse. Sometimes, shared news content both informs and entertains. Indeed, 'sharing to inform' and 'sharing to entertain' appear to exist along a spectrum. Although these are not the only considerations made when news and non-personal content is shared, we postulate that every instance of news sharing involves informing, entertaining, or some combination of the two.

Mariposa \& Carl, for instance, describe examples where they posted content on Facebook to inform friends and followers about specific events how to learn more about them:

Mariposa: [What] I posted was a message to everyone saying that I was going to a reptiles-at-risk workshop this upcoming weekend, and so if anyone was interested, they should contact me.

Carl: $[\mathrm{M}] \mathrm{y}$ fraternity is organizing an event this weekend for a campout for mental health. I was sharing pictures and articles about that... TED talks... articles that people have written about the events in past years, pictures from past years, that kind of stuff.

Patrice makes a deliberate choice to share content that is humorous, entertaining and positive:

Patrice: [W] hat I'm posting is geared towards my friends to see.... I wanna bring to the table those little funny things that they can look at during the day and have a little laugh.... This video that I saw about that Kid President who is saying little things that people should do more often, like say "Thank you", say "I'm sorry," "give people corn dogs" and stuff like that. That's the type of thing I would share to make people have like a little highlight.

Participant comments indicated that the intended recipient(s) played a part in the decision to share news. Informing' and 'entertaining' focus on the recipient: the sharer passes along news and information because they believe that the content will have informational or entertainment value for the receiver(s). Both informing and entertaining are more about the audience than the sharer. This focus is evident in participants' comments when describing how they share and with whom. When sharing news and non-personal content, most participants considered whether the content was (i) worthy enough to share before they clicked the send/post/share button and (ii) relevant to their audience. Vivian, for instance, describes her process when sharing non-personal content. She indicates her reaction to research she finds interesting and then considers the relevance or benefit to her audience:

Vivian: [I]f I care enough to go and find it online, it means that it's interesting to me. I probably want to remember it. And I probably think that it's useful to someone else. And I also probably think that it's not widely known.

\subsection{Other Influencing Motivations}

While the basic decision of whether content is 'shareable' reflects consideration of the potential to inform/entertain, individual sharing events reflect a variety of other motivations. Analysis of individual participant comments revealed four such motivations: maintaining connection, changing minds, distinguishing oneself, and being part of the crowd. In this section, we describe each of these motivations and provide examples. 


\subsection{1 'Maintaining Connection'}

Many instances involve one person sharing a news item with an individual or small group based on a previous knowledge (or perception) that it may be of interest to the recipient(s). This act of sharing appears to be informing in the simplest sense: the focus is on the recipient and the sharer's perceived notion that they might appreciate the content forwarded to them. This form of sharing is targeted and specific-the item is specific to the recipient(s) and often shared in a private message, email, on the recipient's wall, or tagged.

For instance, Patrice described an instance where she shared an article based on a previous conversation with a friend:

Patrice: I just shared that article of a python who ate a drunk guy in India who was passed out next to a liquor store. I thought it was funny, and I had a discussion with a friend about pythons, so I shared it on his wall.

Patrice recognizes that the content may have some benefit or interest to her friend and decides to share the content to inform the recipient. This instance of sharing also reinforces a connection between sharer and recipient - a signal that the sender may have the same interest, or, at the very least, understands the potential interest or amusement for their recipient.

Vivian: [I]n my case, it has to do with the relationship and what I know about the other person. So, with [my friend], it's an ongoing joke, it's something that we share. With [people at work], it's about "I think I know what you're interested in, and here's something that I think might be valuable for you."

Sharing directly with a select group or individual is an effort to maintain, nurture, or cultivate the relationship between the sharer and recipient(s). It appears to be based on an ongoing conversation or history, one where the sharer notices and understands how an article or link to something may be of benefit to the recipient. This reinforces Harris [9]: "It is a way of tangibly demonstrating to their networks that they are thoughtful and caring, and gives an excuse to reinforce their position with an individual."

\subsection{2 'Changing Minds'}

Some people are motivated to share news content online to voice concerns and praises about issues that are important to them. One consideration when sharing non-personal content is to promote personal causes, to inform and potentially change the way others act or perceive an issue/event. Bobbi, for instance, chooses to post content on Facebook about animal cruelty and animal rights to the point of proselytizing: "[V]eganism is my religion. I want everyone to be vegan." She stated outright that social media is a platform where she expresses her personal beliefs: "I sometimes feel like it's overwhelming because I end up finding that my personal belief system and wanting everyone else to be aware of it, spills into all of my social media." Bobbi shares content in hopes for a response to what she posts. She is driven to share in hopes of influencing others to make choices that follow her belief system.

In contrast to Bobbi, Sheree is more selective in the content she shares; her motivation to share certain content is influenced by her audience. Sheree shares issues that matter to her but also takes into consideration the relevance and readability of these issues to her network. For example, she feels strongly enough to share content surrounding the riots in Ferguson, but balks at sharing articles she calls 'dense' as she perceives them to be less accessible to her audience. Unlike Bobbi, Sheree is concerned that the members of her 
social network may overlook the content she posts if they find it irrelevant or written with too much jargon. Sheree's comments suggest that her efforts to call attention to issues, albeit subtler than Bobbi's, is still a form of sharing with the intention to change others' attitudes or perspectives. She does not want to alienate her audience by posting content that is challenging for them to understand. Instead, she wants to introduce content that will make them think more critically about those issues.

Armand believes in influencing people's opinions and perspectives through sharing controversial content. He reported that he is often compelled to share material that may be contentious for friends, family and acquaintances in his home country:

Armand: [W]hen I feel strong about something, going to post and tell my people in [my home country] "You are wrong."...I posted a video about empowerment of women and empowerment of their body specifically... it was about the 'right' proportion[s]. I regret it so much because people in [my home country] are very conservative. And it just [makes explosion sound] Whoosh! I was like "Oh, what did I do?"

Armand stated that in the past he was more "outspoken" on social media, but confessed that he is now hesitant to share items that will spark lengthy discussion. He refrains from posting provocative material because he feels he does not have enough time to argue in what seems to be an inevitable debate:

Armand: If I feel strong about it today, at that particular time, that particular minute, then I'm going to click 'share'. But if I am overwhelmed with many other things, I'm not going to do it just because I could propagate a discussion that I don't want to on my Facebook. ...In the past, I was more intense about things I care [about]. Now, ... it's just too much.

Tommy is straightforward about posting any content he feels strongly about and clearly defined his goal to "spread" his point of view: Most of the time if I were to post something, it'd be to push an agenda which I think it is for a lot of people. If it's not like a joke or something, it's to try to convince people of your point of view or try to spread your point of view.

Most of the participants echoed Tommy's sentiment, indicating if something is worth sharing, it would be something that had value and would spark discussion.

\subsection{3 'Distinguishing Oneself'}

Some participants' comments indicated an apparent need to be the first to post breaking news, to be at the forefront of a trend, to be unique and different from everyone else in their social network. "Distinguishing oneself" is deliberately sharing news and non-personal content that is unique and unlike any other content that exists within one's social network.

Marie, for instance, chooses to post content on her Facebook timeline that she believes is novel to her friends and followers: "I take things from outside and bring them to Facebook.... A band that I like that is not very well known... I'll just share a song." Marie makes a point of posting content that is different from trending news and events. In another example, she described posting details on other world events during the widespread coverage of the Charlie Hebdo mass shooting and its aftermath:

Marie: I also felt the need to share other news because everybody around the world was like "Je Suis Charlie, oh my God." I don't want to sound insensitive because I was... I'm French, and I was in France, and it was terrible. But other awful things were happening in the world. And everybody was forgetting it, being like, "Oh my God, 10 people got killed in France. This is awful." But in the meantime, 200 people got killed in Africa the same day, and nobody mentioned it. So, I was trying to also share things like that and to try to make people aware of stuff like that. 
While this seems like a conscientious action to broaden her friends' and followers' perspectives by posting news about tragedy in Africa, it appears as though Marie intentionally chose not to post content related to Je Suis Charlie. This also implies an underlying desire to be a distinct voice amongst the extensive coverage of the mass shooting at the Charlie Hebdo offices.

Similar to Marie, Carl appears to be driven to share unique content with members of his social network. He also referenced music and content that may be obscure to his audience: "I think the stuff I post the most is stuff that I know people haven't seen yet. The second that the OVO lineup for Drake this summer, I shared it and not a lot of people had seen it." Carl also chooses not to share items that he believes will soon saturate social media:

Carl: That's why if a new music album comes out, or something like that, I don't feel the need to share that because it's going to get big. Either way, whether you share it or not, it's going to get big.

Sharing content that distinguishes one's self also involves the decision to avoid sharing content that is widespread. Both Carl and Marie strive to post things that are different from the rest, which is implicitly demonstrated in their choices not to share content that is prevalent. Choosing not to post common or ubiquitous material is another way to stand out from others. Several other focus group participants reported their preference to share content that has not been seen (or shared) by any others in their social network. These participants post information they feel is new to others, often from external sources, and content that has not saturated, or anticipate would saturate, their news feeds (i.e., the content they post would remain unique for some time.)

Tommy: People will share something if they think it hasn't gotten popular yet. If they think "I'm going to spread this to my Facebook friends 'cause maybe they haven't seen it yet." But if something is already popular, like the Kony thing, for example, there's no reason to share it 'cause everyone's already [seen it]. Or like, the [Black \& Blue] dress thing. You know that everyone [saw] it happens to post it again. If you see it 100 times on your wall, you're like "Oh cool." But a million people have already...

Vivian: [I]f I thought it was of interest to everybody, I would assume they knew about it. And, if I thought it was of interest just to me, then I would assume they wouldn't be interested. So, there's no... I would never think of myself as being the first responder with respect to news.

Other participants indicated posting trending material is pointless and some suggest that re-sharing content that is quickly saturating the social media and beyond is an annoyance:

Heather: [W] hen it's everywhere, you are not going to gain anything by posting it [on] your wall because it's already everywhere.

Vivian: I don't tend to forward on things that I think are going to be widely known. It's, like, what's the point? 'Cause I could plug up people's lives, I don't want to do that.

Billy: I was sure all my friends at seen at that point....But, by the time I got my hands on it, it was already too late. And I couldn't unviral it.

Sharing to distinguish focuses on presenting content that is unique. Unlike 'informing' and 'entertaining', 'distinguishing oneself' appears to be less about the recipients and more about the sharer and the considerations they make about the content they choose to share.

\subsection{4 'Being Part of the Crowd'}

One participant described an instance of re-sharing news content that was not meant to benefit anyone in particular or meant to change others' attitudes. 'Being part of the crowd' 
involves sharing information that is not unique, rather it is re-sharing content as part of a larger online social event or community.

Corin, for instance, describes her reaction to the documentary Blackfish that prompted news coverage on the controversy over orcas held in captivity at SeaWorld:

Corin: That movie about the orcas that came out a couple of years ago and it was all over Facebook for a while, and that got me really riled up. So, I followed a couple of groups that re-blogged a lot of articles that were bashing Sea World...[I]t happened for a couple of months, and then it faded away. Obviously, as a person who hopped on the bandwagon, I stopped re-sharing, sharing that stuff.

Corin's motivation to share this content is slightly different than the sharers motivated to change others' attitudes or to be unique in what they post. On the surface, sharing content that others may already be aware of may be to emphasize the importance of the issue to members of her social network, but she appears to be less concerned with proselytizing and more interested in signaling that these issues are deeply important to her. This re-sharing of content, perhaps, may be a function of this motivation; for Corin, re-sharing news about orcas in captivity was an opportunity to present an issue and associate herself with a particular community.

Viral phenomena may be a result of this type of sharing. Millions of people re-share viral content on their wall despite knowing others may have seen it. What else might explain viral memes such as "The [Blue and Black] dress" in 2015? The photo of the dress of questionable colour resulted in a meme that sparked an Internet-wise debate and permeated news sites and eventually broadcast media. When asked about the dress meme, many of the focus group participants commented that it was pointless to re-share the meme because it was everywhere:

Carl: Once I saw four people had already posted [the black and blue dress], there was absolutely no reason for me to post it because it was going to get big. Because I could tell, everyone's going to go into a frenzy about this kind of thing.

Ashley: I think the dress just happen so fast that a bunch of people... like, everyone saw it at once kind of thing. So, everyone thought they were the first ones to see it. By the time I saw it, my Facebook wall was full of it.

These comments, however, seem to contradict the results of the viral phenomenon. If it was pointless to share the content, enough even to take it down after posting it, then how exactly did the phenomenon become viral? Further analysis reveals that jumping on the bandwagon and sharing the meme satisfied the desire to interact with others and participate in the group (and global) discussion. The dress meme encouraged interaction and debate throughout social networks, online and offline. This type of sharing is driven by the need to feel part of a community, to participate in a global-scale conversation, to interact in socially with trending topics and to contribute as a member of a larger online social event.

\subsubsection{News Sharing vs. Personal Sharing}

These results suggest that motivations for sharing news online are similar to sharing personal content online; nonetheless, the findings indicate that some important differences between the two types of sharing. The sharing of either type of information reveals (for better or worse) aspects of the self, although these revelations are arguably more significant when personal information, as opposed to news or other non-personal content, is shared. Thus, a distinction can be made between the sharing of news - that is bringing attention to 
"something you should know about"-and sharing personal information - that is, bringing attention to "something I want you to know about me."

The benefits of sharing both personal and non-personal content can include self-fulfillment, feeling part of a community, and shaping and strengthening relationships. Non-personal content, however, is also shared to benefit others - a motivation that does not appear to operate (at least to the same degree) in the sharing of personal content. The decision to share news appears to be based on an assessment of the value of this content to the audience: Is this interesting and important enough for me (and for the recipient) to share with this audience?

\section{CONCLUSION}

This research is an exploratory study of factors that influence our decision to share and reshare news with others in an online environment. Informing and entertaining are underlying considerations in all instances of news and non-personal sharing. These considerations appear to be audience-focused - that is, the motivation to share news is at the very least intended to inform and entertain the intended recipient. Maintaining connection, changing minds, distinguishing oneself, and being part of the crowd are other considerations that influence the 'base' motivations informing and entertaining. Through the analysis of participant comments and discussion, we attempt to describe the characteristics of each of these influences on the motivation to share news online. They stem from a personal desire/need to (respectively): maintain relationships, change other's attitudes, present themselves as unique, or belong to something larger. We posit that these considerations can intermingle, with varying degree, in any given instance of news sharing. They may not, however, be the only considerations that exist in this news sharing process.

While the comments from these participants reflect views and perspectives from 2015, it would be interesting to compare the collected data with new data that reflects current political, cultural, and global climates and to observe any differences in the results. It is also important to consider the changes in news consumption and potential its influence on the outcomes of significant events.

This study examined the factors that influence the decision to share news in an online environment from a broad perspective, but further research is necessary to explore these factors at a granular level. Gathering specific instances of news sharing and investigating the relationships between sharer, content, and intended recipient we can: (i) confirm more examples of these considerations, (ii) investigate and describe the confluence of audience, content, and these considerations, and (iii) observe how all of these elements may interact.

\section{REFERENCES}

[1] Barthel, M., Shearer, E., Gottfried, J., \& Mitchell, A. (2015, July 14). The evolving role of news on Twitter and Facebook. Retrieved from: http://www.journalism.org/2015/07/14/theevolving-role-of-news-on-twitter-and-facebook/

[2] Barthel, M., Shearer, E., Gottfried, J., \& Mitchell, A. (2015, July 14). News Habits on Facebook and Twitter. Retrieved from http://www.journalism.org/2015/07/14/news-habits-onfacebook-and-twitter/

[3] Berger, J., \& Milkman, K. L. (2012). What makes online content viral? Journal of Marketing Research 49, 2, 192-205. doi:10.1509/jmr.10.0353

[4] Bivens, R. (2014). Digital Currents: How Technology and the Public Are Shaping TV News. University of Toronto Press. 
[5] Bjoran, K. (2011). Viral content: Why we share some things and not others. Retrieved from http://sixrevisions.com/content-strategy/viral-content-why-we-share-some-things-and-notothers/

[6] Chang, L. (2016, July 9). The generation most likely to share content on Facebook? Baby boomers. Retrieved September 17, 2017, from http://www.digitaltrends.com/socialmedia/facebook-sharing-content/

[7] Forgas, J. P., Williams, K. D., \& Laham, S. M. (2005). Social Motivation: Conscious and Unconscious Processes (Vol. 5). Cambridge University Press.

[8] Gottfried, J., \& Shearer, E. (2016, May 26). News use across social media platforms 2016. Retrieved from http://www.journalism.org/2016/05/26/news-use-across-social-mediaplatforms-2016/

[9] Harris, Z. (2016, September 12). Stop obsessing with digital sneezers - start thinking about discerning sharers. Retrieved from http://www.thedrum.com/opinion/2016/09/12/stopobsessing-with-digital-sneezers-start-thinking-about-discerning-sharers

[10] Hermida, A. (2014). Tell Everyone: Why We Share and Why It Matters. Toronto: Doubleday Canada.

[11] Mitchell, A. (2015, April 29). State of the news media 2015. Retrieved from http://www.journalism.org/2015/04/29/state-of-the-news-media-2015/

[12] Mitchell, A., \& Holcomb, J. (2016, June 15). State of the news media 2016. Retrieved from http://www.journalism.org/2016/06/15/state-of-the-news-media-2016/

[13] Siemens, L. (2011). The balance between on-line and in-person interactions: Methods for the development of digital humanities collaboration. Digital Studies / Le Champ Numérique 2,1. Retrieved from https://www.digitalstudies.org/ojs/index.php/digital_studies/article/view/184

[14] Strauss, A. L. (1998). Basics of Qualitative Research: Techniques and Procedures for Developing Grounded Theory (2nd ed.). Thousand Oaks: Sage Publications.

[15] The New York Times. (2012). The psychology of sharing. [PDF presentation media kit] Insights. Retrieved from http://nytmarketing.whsites.net/mediakit/pos/

[16] Turner, J. H. (1988). A Theory of Social Interaction. Stanford University Press. 